\title{
Sensitivity of Monilinia fructicola from Peach Farms in China to Four Fungicides and Characterization of Isolates Resistant to Carbendazim and Azoxystrobin
}

S. N. Chen, Y. Shang, and Y. Wang, College of Plant Science and Technology, Huazhong Agricultural University, Wuhan 430070, China; G. Schnabel, School of Agricultural, Forest and Environmental Sciences, Clemson University, Clemson, SC 29634; and Y. Lin, L. F. Yin, and C. X. Luo, College of Plant Science and Technology and the Key Lab of Crop Disease Monitoring \& Safety Control in Hubei Province, Huazhong Agricultural University

\begin{abstract}
Brown rot of peach caused by Monilinia fructicola can cause considerable preharvest and postharvest losses in China. Fungicides are increasingly utilized to minimize such losses. Eighty isolates of $M$. fructicola were collected from commercial peach orchards located in five provinces in China and the sensitivity to carbendazim, azoxystrobin, tebuconazole, and boscalid was determined. Resistance to carbendazim was detected only in the Yunnan province in 15 of 16 isolates. Characterization of carbendazim-resistant isolates revealed stable resistance, no fitness penalty, and negative cross resistance to diethofencarb. Resistant isolates produced disease symptoms on detached fruit sprayed with label rates of formulated carbendazim and possessed the amino acid mutation E198A in $\beta$-tubulin. Resistance to azoxystrobin was detected in 3 of 10 isolates from Fujian. In contrast to carbendazim
\end{abstract}

Abstract

Chen, S. N., Shang, Y., Wang, Y., Schnabel, G., Lin, Y., Yin, L. F., and Luo, C. X. 2014. Sensitivity of Monilinia fructicola from peach farms in China to four fungicides and characterization of isolates resistant to carbendazim and azoxystrobin. Plant Dis. 98:1555-1560.

resistance, however, azoxystrobin resistance was unstable, associated with a fitness penalty, and not associated with mutations in the target gene cytochrome $b$. The concentration at which mycelial growth is inhibited $50 \%\left(\mathrm{EC}_{50}\right)$ values of the azoxystrobin-sensitive isolates were 0.02 to $1.94 \mu \mathrm{g} / \mathrm{ml}$, with a mean value of $0.54 \mu \mathrm{g} / \mathrm{ml}$. All isolates were sensitive to tebuconazole, with a mean $\mathrm{EC}_{50}$ value of $0.03 \mu \mathrm{g} / \mathrm{ml}$. The $\mathrm{EC}_{50}$ values for boscalid were 0.01 to $3.85 \mu \mathrm{g} / \mathrm{ml}$, with a mean value of $1.02 \mu \mathrm{g} / \mathrm{ml}$. Our results indicate that methyl benzimidazole carbamates (MBCs), quionon outside inhibitors, demethylation inhibitor fungicides, and succinate dehydrogenase inhibitors are likely to be very effective in controlling brown rot in many peach production areas in China, but that resistance to MBCs is emerging.
China produces more peach fruit (Prunus persica L. Batsch) than any other country in the world, with a total production of 10 to 12 million tons per year (2). Many pests and diseases challenge production in China but one of the most economically important diseases is brown rot caused by Monilinia spp. For many years, it was assumed that brown rot was caused by Monilinia fructigena, $M$. laxa, and M. fructicola but, according to the most recent characterization of isolates from all major production areas, including Beijing, Shangdong, Hebei, Zhejiang, Fujian, Hubei, Shaanxi, Gangsu, Chongqing, and Yunnan provinces, the only species involved in brown rot disease are M. fructicola, M. mumecola, and M. yunnanensis. Among those species, $M$. fructicola is the most widely distributed species in China (12). It can cause blossom blight, twig canker, and pre- and postharvest fruit rot $(11,23)$.

Fungicide application is an important component of the management of this disease in most production areas worldwide, including China. Although growers in the United States and Europe primarily use site-specific fungicides, including methyl benzimidazole carbamates (MBCs), quinone outside inhibitors (QoIs), demethylation inhibitors (DMIs), and succinate dehydrogenase inhibitors (SDHIs) for preharvest brown rot control, Chinese farmers typically use sulfur and mancozeb. Due to the typically inferior efficacy of the latter fungicides compared with many site-specific fungicides, the viability of the industry in many provinces relies heavily on sanitation practices such as canker removal, removal of diseased fruit, and individual bagging of fruit (8). Site-specific fungicides are used sporadically by some Chinese farmers for preharvest peach brown rot control. In particular, MBCs, including carbendazim and

Corresponding author: C. X. Luo, E-mail: cxluo@ mail.hzau.edu.cn

Accepted for publication 1 May 2014.

http://dx.doi.org/10.1094/PDIS-11-13-1145-RE

(C) 2014 The American Phytopathological Society thiophanate-methyl, have been used in some areas. It is expected that, with the expiration of patents, generics of many active ingredients such as azoxystrobin and some DMIs will enter the Chinese fungicide market at prices affordable for many producers.

Site-specific fungicides are prone to resistance development, especially when used frequently and exclusively. Resistance in $M$. fructicola to MBCs has been reported worldwide $(7,12,25-29,36)$, including in northern China (9). DMI fungicide resistance was reported first more than 20 years after introduction in the 1980s and is not as widespread compared with MBCs. Resistance has been reported in the eastern United States $(3,20,30)$ and Brazil (26). A shift toward reduced sensitivity to azoxystrobin was reported in isolates from New York (34), South Carolina, Georgia (1), and Brazil (26); and reduced sensitivity to SDHIs, an inhibitor of dehydrogenization of succinate, has only been described in isolates from a single location in South Carolina (1).

The increasing interest and use of site-specific fungicides in China justifies assessments of sensitivity in populations over time to track sensitivity shifts. The objectives of this study were to determine the sensitivities of $M$. fructicola isolates from important peach-growing provinces in China to carbendazim, azoxystrobin, tebuconazole, and boscalid, and to characterize resistant isolates.

\section{Materials and Methods}

Collection of $M$. fructicola isolates. Eighty single-spore isolates of M. fructicola were obtained between 2009 and 2012 from major peach-production provinces in China (Table 1). The orchards had rarely been exposed to site-specific fungicides, except for the MBCs carbendazim and thiophanate-methyl. For long-term storage, isolates were maintained on dried filter paper. Briefly, colonies were grown on potato dextrose agar (PDA; $200 \mathrm{ml}$ of juice from $200 \mathrm{~g}$ of potato, $20 \mathrm{~g}$ of dextrose, and $20 \mathrm{~g}$ of agar per liter) in petri dishes starting with mycelial plugs, and sterile filter paper discs ( $5 \mathrm{~mm}$ in diameter; Haier) were placed on the agar surface at the beginning of the incubation period. Each isolate was grown at $22^{\circ} \mathrm{C}$ for about 4 days in darkness. After the filter discs were cov- 
ered with mycelium, they were removed and placed into a desiccator with silica gel. After 7 days, discs were transferred into $1.5-\mathrm{ml}$ sterile centrifuge tubes with desiccated silica gel and stored at $-20^{\circ} \mathrm{C}$. All of the 80 isolates collected were identified to species level based on their morphological characteristics and polymerase chain reaction (PCR) identification, as described previously (12).

Fungicides. Technical-grade carbendazim (97\% a.i.; Jinbei Chemical Co., Ltd.), azoxystrobin (96\% a.i.; Gengyun Co., Ltd.), boscalid (97\% a.i.; Kangbaotai Chemical, Co., Ltd.), tebuconazole (96\% a.i.; Sheyang Huanghai Pesticides and Chemical Co., Ltd.), and diethofencarb (95.4\% a.i.; Lanfeng Chemical Co., Ltd.) were used in this study. Stock solutions were made by dissolving each fungicide in acetone at the concentration of $8,000 \mu \mathrm{g}$ a.i./ml, except for carbendazim and azoxystrobin, which were dissolved in 0.2 $\mathrm{mol} /$ liter $\mathrm{HCl}$ and methanol, respectively. The stock solutions were stored at $4^{\circ} \mathrm{C}$ in darkness. Salicylhydroxamic acid (SHAM) was added to azoxystrobin-amended PDA at $60 \mu \mathrm{g} / \mathrm{ml}$ to suppress the alternative oxidase pathway. Corresponding control dishes contained SHAM.

In vitro sensitivity of $M$. fructicola to carbendazim, diethofencarb, azoxystrobin, tebuconazole, and boscalid. Sensitivity to carbendazim, azoxystrobinm and tebuconazole was assessed on fungicide-amended PDA at $0,0.03,0.1,0.3,1,3,10$, and $30 \mu \mathrm{g}$ a.i./ml. Carbendazim-resistant isolates were subjected to a second series of sensitivity assays involving PDA amended with carbendazim at $0,100,200,300,400$, and $500 \mu \mathrm{g}$ a.i./ml. Additional assays were conducted for azoxystrobin-resistant isolates at 1, 3, 10, 20, and $30 \mu \mathrm{g}$ a.i./ml. Boscalid was added to minimal medium $(\mathrm{MM})$ at final concentrations of $0,0.03,0.1,0.3,1,3$, and $10 \mu \mathrm{g}$ a.i./ml. The MM contained $10 \mathrm{~g}$ of glucose, $1.5 \mathrm{~g}$ of $\mathrm{K}_{2} \mathrm{HPO}_{4}, 2 \mathrm{~g}$ of $\mathrm{KH}_{2} \mathrm{PO}_{4}, 1 \mathrm{~g}$ of $\left(\mathrm{NH}_{4}\right) \mathrm{SO}_{4}, 0.5 \mathrm{~g}$ of $\mathrm{MgSO}_{4} \cdot 7 \mathrm{H}_{2} \mathrm{O}, 2 \mathrm{~g}$ of yeast extract, and $12.5 \mathrm{~g}$ of agar per liter. To inoculate test plates, mycelial plugs were removed with a 4-mm cork borer from the margins of 5-day-old colonies and placed upside down on the centers of 9$\mathrm{cm}$ plastic petri dishes containing the fungicide-amended or unamended media. Each isolate was tested in triplicate and plates were incubated at $22^{\circ} \mathrm{C}$ for 5 days in darkness. Mean colony diameter (minus the diameter of the inoculation plug) was measured for each treatment and expressed as percent growth inhibition. The $\mathrm{EC}_{50}$ values represent an assessed concentration at which mycelial growth is inhibited $50 \%$, as assessed by regressing percentage of mycelial growth inhibition against the $\log _{10}$ of fungicide concentrations.

Pathogenicity assay on detached fruit. Peach fruit of similar size and commercial maturity were washed in $75 \%$ ethanol and rinsed with sterile water to remove potential pesticide residues. Fruit was placed in plastic boxes until the surface had dried, then inoculated and assessed for disease incidence 2 days after inoculation. Fruit used for evaluation of fungicide control efficacy was sprayed with the highest labeled rates of formulated carbendazim (0.83 g a.i./liter; Jinbei Chemical Co., Ltd.) or azoxystrobin $(0.13 \mathrm{~g}$ a.i./liter; Gengyun Co., Ltd.) at $12 \mathrm{~h}$ before inoculation. For inoculation, three 4-by-2-mm (diameter by depth) plugs were removed from each fruit at three equidistant locations $(2 \mathrm{~cm}$ apart) using a cork borer (4 $\mathrm{mm}$ in diameter). A 4-by-2-mm plug taken from the periphery of a 4-day-old colony grown on PDA was inserted upside down into each of the prepared peach holes. Peach fruit treated with azoxystrobin were inoculated with a spore suspension because the mycelial plug method did not effectively control sensitive isolates. Conidia were washed off the 8-day-old colonies with deionized water and adjusted to $10^{5}$ conidia/ml, and fruit were injected with $10 \mu \mathrm{l}$ of conidial suspension to an approximate depth of $4 \mathrm{~mm}$ below the epidermis using a syringe with a $0.9-\mathrm{mm}$-diameter needle. After inoculation, peach fruit in nonbranded plastic trays were covered with cling film to keep the relative humidity around $100 \%$ and maintained at room temperature. Lesion diameters were measured and disease incidence was expressed as the percentage of wounds infected compared with the total number of wounds inoculated. The experiment was conducted twice in a randomized complete block design with three fruit per treatment and three replicates per fruit.

Investigation of mycelial growth and sporulation in vitro. Mycelial growth rates of three carbendazim-resistant isolates (YHC11-8, YHC11-15, and YHC11-17), two azoxystrobin-resistant isolates (FJC10-5a and FJC10-7a), and three sensitive isolates (HG12-4b, ZM09-1a, and BM09-4a) were determined on fungicide-free PDA plates. Mycelium plugs (4 $\mathrm{mm}$ in diameter) taken from the periphery of 5-day-old cultures were transferred to the center of PDA plates and incubated at $22^{\circ} \mathrm{C}$ in the dark. The colony diameters were measured after 4 days, with three replicates per isolate. Mean colony diameters were calculated as daily growth rates. Sporulation was quantified on V8 medium $(200 \mathrm{ml}$ of V8 juice and $20 \mathrm{~g}$ of agar per liter) at $22^{\circ} \mathrm{C}$ in the dark after 9 days. Conidia were rinsed off the medium with $10 \mathrm{ml}$ of sterile water. The suspension was transferred to $50-\mathrm{ml}$ tubes with 10 glass beads and vortexed for $1 \mathrm{~min}$. The concentration of conidia was determined using a hemacytometer. Mean conidia production of three replicates was determined for each isolate. All experiments were conducted twice.

Stability of resistance to carbendazim and azoxystrobin. Isolates maintained for 2 years on filter paper at $-20^{\circ} \mathrm{C}$ were recovered by placing a piece of filter paper on PDA medium and incubating the plates at $22^{\circ} \mathrm{C}$ for 5 days. Mycelium plugs were taken from the periphery of the colonies and transferred to fresh plates. This process was repeated for 5 weeks but new plates were always inoculated with the colony of the previous generation. $\mathrm{EC}_{50}$ values for carbendazim and azoxystrobin were determined before the first and after the last transfer, as described above.

DNA extraction and detection of resistance alleles. Isolates were grown on PDA at $22^{\circ} \mathrm{C}$ for 5 days in darkness. Single agar plugs containing actively growing mycelium were transferred to 40 $\mathrm{ml}$ of potato dextrose broth $(200 \mathrm{ml}$ of juice from $200 \mathrm{~g}$ of potato and $20 \mathrm{~g}$ of dextrose per liter) and incubated for 3 days. Mycelia were harvested and rinsed with sterile water, and genomic DNA was subsequently extracted using the Easypure Plant Genomic DNA Extraction Kit (TransGen Biotech). The partial $\beta$-tubulin gene was amplified with primer pair TubA and TubR1 (25). PCR volumes were $50 \mu$, containing $1 \times$ PCR buffer, $50 \mathrm{ng}$ of DNA, 0.4

Table 1. Mean concentration at which mycelial growth is inhibited $50 \%\left(\mathrm{EC}_{50}\right)$ values of Monilinia fructicola populations from China sensitive to carbendazim, azoxystrobin, tebuconazole, and boscalid

\begin{tabular}{lccccc}
\hline & & \multicolumn{4}{c}{ EC $_{\mathbf{5 0}}{\text { to fungicides }(\boldsymbol{\mu g} / \mathbf{m l})^{\mathbf{x}}}$} \\
\cline { 3 - 6 } Province & Number of isolates $^{n}$ & Carbendazim $^{\mathbf{y}}$ & Azoxystrobin $^{\mathbf{z}}$ & Tebuconazole & \multicolumn{1}{c}{ Boscalid } \\
\hline Yunnan & 16 & $0.08 \mathrm{~b}$ & $0.73 \pm 0.34 \mathrm{a}$ & $0.03 \pm 0.04 \mathrm{~b}$ & $0.73 \pm 0.43 \mathrm{~b}$ \\
Beijing & 20 & $0.14 \pm 0.20 \mathrm{a}$ & $0.59 \pm 0.40 \mathrm{~b}$ & $0.07 \pm 0.04 \mathrm{a}$ & $1.40 \pm 0.77 \mathrm{a}$ \\
Fujian & 10 & $0.42 \pm 0.46 \mathrm{a}$ & $0.56 \pm 0.41 \mathrm{~b}$ & $0.02 \pm 0.03 \mathrm{c}$ & $1.25 \pm 1.33 \mathrm{ab}$ \\
Shandong & 11 & $0.06 \pm 0.01 \mathrm{~b}$ & $0.44 \pm 0.437 \mathrm{~b}$ & $0.01 \pm 0.01 \mathrm{c}$ & $1.19 \pm 0.49 \mathrm{ab}$ \\
Hubei & 23 & $0.06 \pm 0.04 \mathrm{~b}$ & $0.42 \pm 0.16 \mathrm{~b}$ & $0.01 \pm 0.01 \mathrm{c}$ & $0.73 \pm 0.64 \mathrm{~b}$ \\
Total & 80 & $0.13 \pm 0.22$ & $0.54 \pm 0.36$ & $0.03 \pm 0.04$ & $1.02 \pm 0.78$ \\
\hline
\end{tabular}

${ }^{x}$ Mean \pm standard deviation; values within the same column followed by the same letters are not significantly different based on the one-way analysis of variance with least significant difference test in SPSS software at $P=0.05$.

${ }^{y}$ Fifteen carbendazim-resistant isolates from Yunnan were not included for baseline sensitivity assay to carbendazim.

z Three isolates with reduced sensitivity to azoxystrobin from Fujian were not included for baseline sensitivity assay to azoxystrobin. 
$\mu \mathrm{M}$ each primer, $100 \mu \mathrm{M}$ each $\mathrm{dNTP}$, and $1 \mathrm{U}$ of Taq DNA polymerase (TransGen Biotech Co.). All amplifications were performed in an iCycler thermal cycler (Bio-Rad Laboratories Inc.). The PCR reaction was performed with the following parameters: an initial preheating for $3 \mathrm{~min}$ at $95^{\circ} \mathrm{C}$; followed by 40 cycles of denaturation at $94^{\circ} \mathrm{C}$ for $40 \mathrm{~s}$, annealing at $50^{\circ} \mathrm{C}$ for $40 \mathrm{~s}$, and extension at $72^{\circ} \mathrm{C}$ for $1.5 \mathrm{~min}$; with a final extension at $72^{\circ} \mathrm{C}$ for $10 \mathrm{~min}$. PCR products were separated by electrophoresis in a $1.5 \%$ agarose gel in Tris-acetate (19) buffer. Sequencing was conducted at Beijing Genomics Institute.

To investigate cytochrome $b(C y t b)$ gene sequences in azoxystrobin-resistant isolates (FJC10-5a and FJC10-7a), total RNA was isolated using Trizol (Invitrogen), according to the manufacturer's recommendations. First-strand cDNA synthesis was carried out using $1 \mu \mathrm{g}$ of total RNA with Revert Aid First Strand cDNA Synthesis Kit, according to the manufacturer's recommendation (Thermo Fisher Scientific Inc.). The corresponding cDNA fragment of the $C y t b$ gene was amplified and sequenced with primers Mc-F (5'-ATGAGAATTTTTAAAAGTCATCCTT-3') and Mc-R (5'-TTACCTACTCGGCTTTTCTT-3').

Data analysis. Significant differences of $\mathrm{EC}_{50}$ values from different populations (isolates from different orchards) were evaluated by one-way analysis of variance with a least significant difference test in SPSS Software (Release 13.0; SPSS Inc.). To determine cross-resistance in isolates to fungicides, the $\mathrm{EC}_{50}$ values were correlated and the correlation coefficients $(r)$ were calculated by SPSS. The $\mathrm{EC}_{50}$ values were transformed to $\log _{10}$ values before analysis.

\section{Results}

Sensitivity of $M$. fructicola populations to carbendazim, azoxystrobin, tebuconazole, and boscalid. All isolates from Beijing, Fujian, Shandong, and Hubei provinces were sensitive to carbendazim and $\mathrm{EC}_{50}$ values were 0.003 to $1.21 \mu \mathrm{g} / \mathrm{ml}$ with a mean $\mathrm{EC}_{50}$ value of $0.13 \mu \mathrm{g} / \mathrm{ml}$ (Table 1). In contrast, all but one isolate from Yunnan province were resistant to carbendazim, with $\mathrm{EC}_{50}$ values greater than $300 \mu \mathrm{g} / \mathrm{ml}$ (Fig. 1A). The frequency distribution of the $\mathrm{EC}_{50}$ values for azoxystrobin was unimodal (Fig. 1B) and values for sensitive isolates were 0.02 to $1.94 \mu \mathrm{g} / \mathrm{ml}$, with a mean $\mathrm{EC}_{50}$ value of $0.54 \mu \mathrm{g} / \mathrm{ml}$ (Table 1). Three isolates from Fujian province had $\mathrm{EC}_{50}$ values of $19.63,9.07,4.08 \mu \mathrm{g} / \mathrm{ml}$ and were considered resistant. The resistance factors (defined as the ratio of $\mathrm{EC}_{50}$ for a fungicide resistant isolate relative to the mean $\mathrm{EC}_{50}$ of the sensitive isolates) were $36.3,16.8$, and 7.6 , respec-

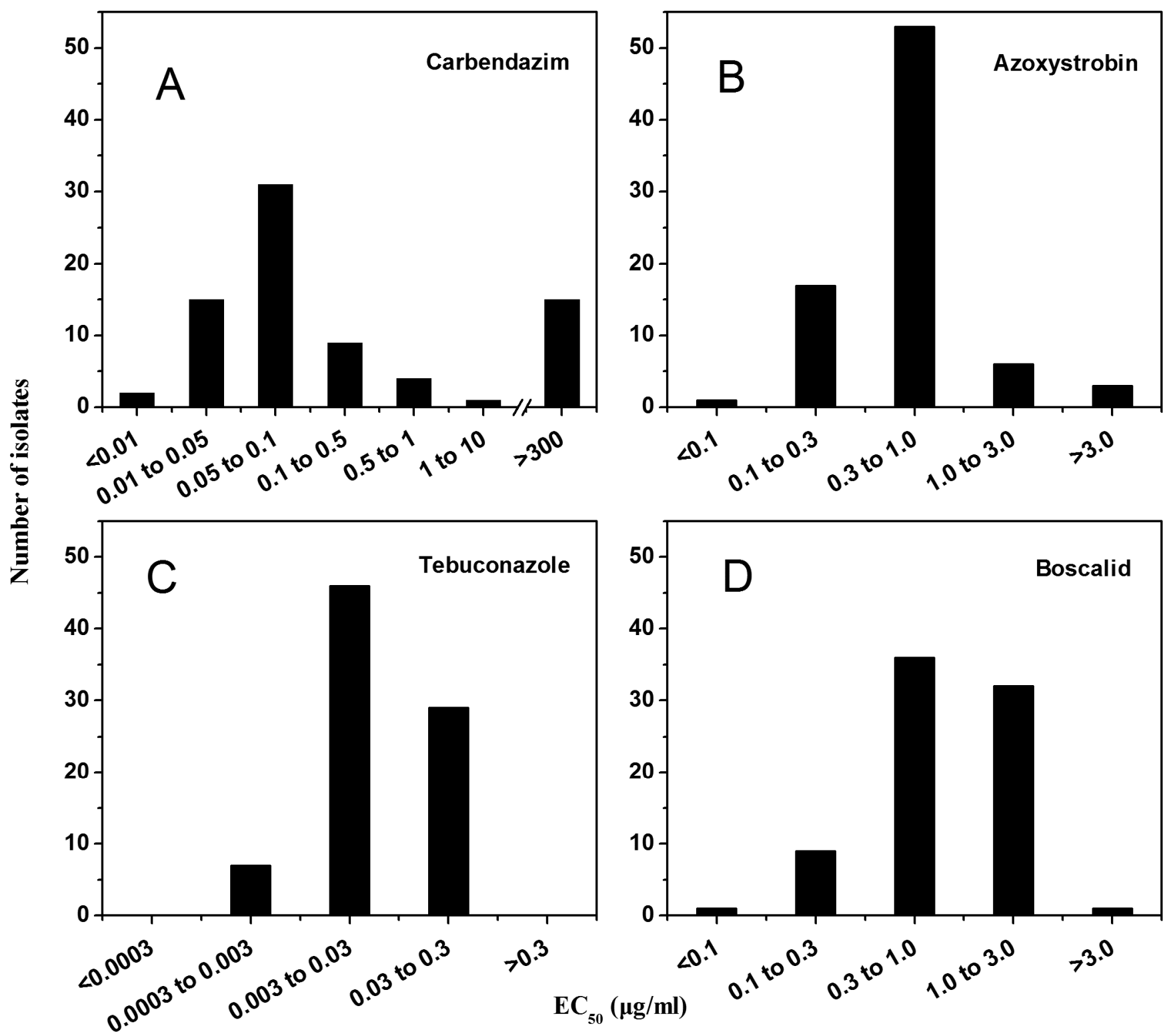

Fig. 1. Distribution of concentration at which mycelial growth is inhibited $50 \%\left(\mathrm{EC}_{50}\right)$ values for $\mathbf{A}$, carbendazim; $\mathbf{B}$, azoxystrobin; $\mathbf{C}$, tebuconazole; and $\mathbf{D}$, boscalid in Monilinia fructicola field isolates from China. 
tively. The distribution of the $\mathrm{EC}_{50}$ values for tebuconazole was unimodal as well (Fig. 1C), ranging from 0.01 to $0.15 \mu \mathrm{g} / \mathrm{ml}$, with a mean $\mathrm{EC}_{50}$ value of $0.03 \mu \mathrm{g} / \mathrm{ml}$ (Table 1). No resistant isolates were detected. $\mathrm{EC}_{50}$ values for boscalid were 0.14 to $2.88 \mu \mathrm{g} / \mathrm{ml}$ (Fig. 1D), with a mean $\mathrm{EC}_{50}$ value of $1.02 \mu \mathrm{g} / \mathrm{ml}$ (Table 1). No resistant isolates were identified.

Among sensitive isolates, there were minute but significant difference $(P<0.05)$ of mean $\mathrm{EC}_{50}$ values of isolates from different provinces (Table 1). The isolates from Fujian and Beijing provinces were less sensitive $(P<0.05)$ to carbendazim compared with those from other provinces, and isolates from Yunnan province were less sensitive to azoxystrobin $(P<0.05)$ compared with all other provinces. The $\mathrm{EC}_{50}$ values for tebuconazole of isolates from Yunnan were significantly lower $(P<0.05)$ than those from Bei-

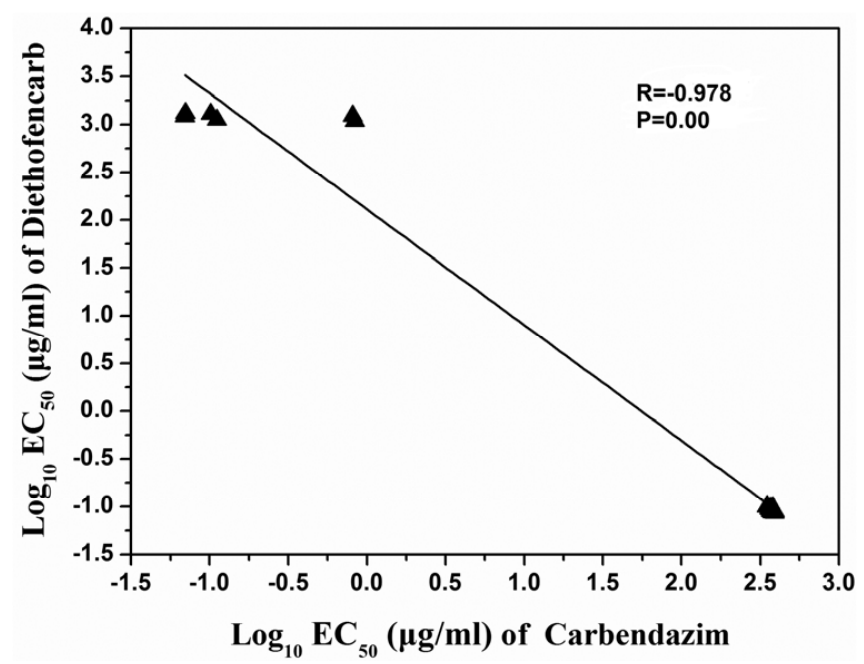

Fig. 2. Correlation of $\log _{10}$-transformed concentration at which mycelial growth is inhibited $50 \%\left(\mathrm{EC}_{50}\right)$ values of Monilinia fructicola isolates for carbendazim and diethofencarb. jing but significantly higher than those from other provinces. The mean $\mathrm{EC}_{50}$ value for boscalid of isolates from Beijing was significantly higher compared with the values from Yunnan and Hubei province. Isolates resistant to carbendazim were sensitive to diethofencarb $(R=-0.987 ; P<0.01$; Fig. 2$)$.

Fitness and stability of resistance in isolates resistant to carbendazim and azoxystrobin. Three fitness components were investigated for three sensitive isolates (HG12-4b, ZM09-1a, and BM09-4a), three carbendazim-resistant (YHC11-8c, YHC11-15c, and $\mathrm{YHC} 11-17 \mathrm{c}$ ) isolates, and two azoxystrobin-resistant isolates (FJC10-7a and FJC10-5a) (Table 2). No significant difference was found in mycelial growth on PDA, ability to sporulate, and lesion size on detached fruit between sensitive and carbendazim-resistant isolates $(P>0.05)$ for all three fitness components (Table 2). Unchanged resistance factors before (RF1) and after (RF2) five weekly transfers on fungicide-free PDA medium indicated that resistance was stable (Table 2). Fitness penalties were recorded for azoxystrobin-resistant isolates. Their ability to sporulate on PDA and to form lesions on detached fruit was reduced compared with the sensitive isolates $(P>0.05)$. Although both isolates were resistant to azoxystrobin after 2 years of storage on filter paper at $-20^{\circ} \mathrm{C}$, they both returned to the level of baseline sensitivity after five weekly transfers on fungicide-free PDA medium (resistance factors decreased from 36.3 and 16.8, respectively, to 1), indicating that the resistance to azoxystrobin was unstable.

Efficacy of carbendazim or azoxystrobin for controlling resistant isolates in vivo. Two carbendazim-resistant isolates (YHC11-8c and YHC11-15c) and one azoxystrobin-resistant isolate (FJC10-7a) were selected for detached fruit assays. FJC10$7 \mathrm{a}$ was selected for these experiments because it showed the least fitness penalty on detached fruit. Sensitive isolate HG12-4b was completely inhibited by carbendazim. In contrast, the carbendazim-resistant isolates YHC11-8c and YHC11-15c caused $100 \%$ disease incidence after 2 days of inoculation and the control efficacies were only 15.5 and $3.0 \%$, respectively (Table 3 ). Using conidia suspensions as inoculum, the azoxystrobin-sensitive isolate HG12-4b was completely controlled. In contrast, the azoxystrobin-

Table 2. Fitness parameters of isolates resistant to carbendazim and azoxystrobin

\begin{tabular}{|c|c|c|c|c|c|c|}
\hline \multirow[b]{2}{*}{ Isolate $^{y}$} & \multirow[b]{2}{*}{ Phenotype $^{z}$} & \multicolumn{2}{|c|}{ Sensitivity to fungicidew } & \multicolumn{3}{|c|}{ Fitness parameters ${ }^{\mathrm{x}}$} \\
\hline & & RF1 & RF2 & Mycelium growth (mm/day) & Sporulation $\left(10^{4}\right.$ conidia $\left./ \mathrm{cm}^{2}\right)$ & Lesion (mm/day) \\
\hline Sensitive & $\mathrm{S}$ & 1 & 1 & $10.76 \pm 0.36 b$ & $18.86 \pm 3.54 \mathrm{a}$ & $23.19 \pm 3.09 \mathrm{a}$ \\
\hline YHC11-8c & Carbendazim-R & $>2,000$ & $>2,000$ & $10.63 \pm 0.19 b$ & $19.02 \pm 2.78 \mathrm{a}$ & $22.23 \pm 2.78 \mathrm{a}$ \\
\hline YHC11-15c & Carbendazim-R & $>2,000$ & $>2,000$ & $11.21 \pm 0.52 b$ & $18.05 \pm 2.65 \mathrm{a}$ & $23.57 \pm 3.45 \mathrm{a}$ \\
\hline YHC11-17c & Carbendazim-R & $>2,000$ & $>2,000$ & $11.03 \pm 0.15 b$ & $18.79 \pm 3.04 \mathrm{a}$ & $23.79 \pm 2.69 \mathrm{a}$ \\
\hline FJC10-7a & Azoxystrobin-R & 36.3 & 1 & $10.27 \pm 0.27 b$ & $9.96 \pm 0.31 b$ & $20.11 \pm 2.29 \mathrm{a}$ \\
\hline FJC10-5a & Azoxystrobin-R & 16.8 & 1 & $12.53 \pm 0.39 \mathrm{a}$ & $7.53 \pm 0.25 \mathrm{c}$ & $19.19 \pm 3.47 \mathrm{~b}$ \\
\hline
\end{tabular}

${ }^{\mathrm{w}}$ Resistance factor (RF) 1 was calculated by dividing the concentration at which mycelial growth is inhibited $50 \%\left(\mathrm{EC}_{50}\right)$ value of the resistant isolate at first transfer by the mean $\mathrm{EC}_{50}$ value of the sensitive population. $\mathrm{RF} 2$ was calculated by dividing the $\mathrm{EC}_{50}$ value of the resistant isolate after the fifth transfer on unamended potato dextrose agar medium by the mean $\mathrm{EC}_{50}$ value of sensitive isolates.

${ }^{x}$ Mean \pm standard deviation; values within the same column followed by the same letters are not significantly different based on the one-way analysis of variance with least significant difference test in SPSS software at $P=0.05$.

y Isolates HG12-4b, ZM09-1a, and BM09-4a represented the sensitive phenotypes and their averaged values are displayed for mycelium growth, sporulation, and pathogenicity.

${ }^{\mathrm{z}} \mathrm{S}=$ sensitive to both carbendazim and azoxystrobin and $\mathrm{R}=$ resistant.

Table 3. Disease incidence and control efficacy on detached fruit treated with formulated fungicides and inoculated with Monilinia fructicola isolates ${ }^{\mathrm{y}}$

\begin{tabular}{|c|c|c|c|c|c|}
\hline \multirow[b]{2}{*}{ Isolate } & \multirow[b]{2}{*}{ Phenotype $^{z}$} & \multicolumn{2}{|c|}{ Disease incidence } & \multicolumn{2}{|c|}{ Control efficacy } \\
\hline & & Carbendazim & Azoxystrobin & Carbendazim & Azoxystrobin \\
\hline HG12-4b & $\mathrm{S}$ & $0 \pm 0 \mathrm{~b}$ & $0 \pm 0 \mathrm{~b}$ & $100 \pm 0 \mathrm{a}$ & $100 \pm 0 \mathrm{a}$ \\
\hline YHC11-8 & Carbendazim-R & $100 \pm 0 \mathrm{a}$ & nd & $15.5 \pm 19.09 b$ & nd \\
\hline YHC11-15 & Carbendazim-R & $100 \pm 0 \mathrm{a}$ & nd & $3.0 \pm 2.83 \mathrm{c}$ & nd \\
\hline FJC10-7a & Azoxystrobin-R & nd & $100 \pm 0 \mathrm{a}$ & nd & $28.5 \pm 3.53 b$ \\
\hline
\end{tabular}

y Disease incidence was expressed as the percentage of wounds infected compared with the total number of wounds inoculated. Control efficacy was expressed as the percentage of the mean diameter of the control minus the mean diameter of the treatment divided by the mean diameter of the control. Data shown are the means of two independent experiments. Mean \pm standard deviation; values followed by the same letter within a column for each experiment separately are not significantly different according to Student's $t$ test at $P=0.05$.

${ }^{\mathrm{z}} \mathrm{S}=$ sensitive to both carbendazim and azoxystrobin, $\mathrm{R}=$ resistant, and $\mathrm{nd}=$ not detected. 
resistant isolate $\mathrm{FJC10}$-7a caused $100 \%$ disease incidence, and the control efficacy was only $28.5 \%$ (Table 3 ).

Nucleotide sequence analysis of the $\beta$-tubulin and $C y t b$ genes. Sequencing analysis of the partial $\beta$-tubulin gene from all 15 carbendazim-resistant isolates revealed a nucleotide change at codon 198 from GAA (glutamic acid) to GCA (alanine). No other amino acid variations were found between sensitive and resistant isolates. The full-length cDNA sequences of $C y t b$ genes were cloned and sequenced from all three azoxystrobin-resistant isolates but no nucleotide variations were found. This indicated that the transient resistance was caused by mechanisms other than mutations in the $C y t b$ gene.

\section{Discussion}

Highly efficacious, site-specific fungicides are not yet commonly used by Chinese peach growers but it is expected that this may change in the foreseeable future. Many generic fungicides are being registered and made available to growers at reduced prices. For this reason, we determined the sensitivity of $M$. fructicola isolates to four fungicides that represent chemical classes that may be used more frequently in the future by Chinese farmers. Our data show that resistance in M. fructicola to MBCs, QoIs, SDHIs, and DMIs was rare or absent, indicating that, in many areas of China, all four chemical classes can be expected to perform to expectations. Only in one province resistance with field relevance to carbendazim was identified.

Resistance to benzimidazoles is common in M. fructicola. MBC-resistant isolates have been reported in the United States since 1976 (14,25,27,32); in Brazil (26) in 2011; in Korea (19) in 1999; and from Beijing and Shandong provinces in China in 2009 (13). Interestingly, all MBC-resistant isolates of this study were collected from Yunnan province, a southwestern province which is more than 2,000 km away from Beijing and Shandong, where $\mathrm{MBC}$ resistance has been described before in $M$. fructicola isolates (9). We do not know how widespread resistance is because of the few locations sampled; however, this study does show that there are still many locations where MBCs should be very effective. Monitoring of resistance may need to be conducted more frequently if more growers use MBCs due to their vulnerability to resistance development. Negative cross resistance between carbendazim and diethofencarb was observed in carbendazimresistant isolates. Diethofencarb inhibits benzimidazole-resistant but not benzimidazole-sensitive isolates $(15,18)$, which is why a mixture of these two fungicides may have the potential to provide control of benzimidazole-resistant isolates in Yunnan province. Resistance is primarily based on the E198A mutation in $\beta$-tubulin $(9,25)$ but some exceptions were reported. Ma et al. (24) investigated low-level resistance in $M$. laxa to benzimidazole and an associated point mutation at codon 6 of the $\beta$-tubulin gene changing histidine to tyrosine. The E198K mutation (16), the E198Q, and the F200Y (6) were reported to be associated with high levels of resistance to MBCs in $M$. fructicola. In our research, only highly resistant isolates were detected and the mutation was confirmed to be the E198A, the same mutation detected in California and North China $(9,25)$.

The baseline sensitivity to azoxystrobin was reported for populations collected in the United States and Brazil. Amiri et al. (1) determined $0.15 \mu \mathrm{g} / \mathrm{ml}$ as the baseline for M. fructicola from South Carolina and Georgia. Louise et al. (26) considered 0.05 to 0.13 $\mu \mathrm{g} / \mathrm{ml}$ as baseline references for isolates from Brazil. Our research showed a higher mean $\mathrm{EC}_{50}$ value $(0.54 \mu \mathrm{g} / \mathrm{ml})$ for the isolates of the sensitive population. The $\mathrm{EC}_{50}$ values were similar to those reported for Chinese isolates (21). The higher $\mathrm{EC}_{50}$ values of the Chinese isolates could have been caused by the lower dose (60 $\mu \mathrm{g} / \mathrm{ml}$ ) of SHAM added to the test media in this study and in the other study from China (10) compared with the U.S. study (22).

In our study, isolates with $\mathrm{EC}_{50}$ values of 19.6, 9.07, and 4.08 $\mu \mathrm{g} / \mathrm{ml}$ were observed. Villani and Cox (34) observed a shift in the sensitivity of $263 \mathrm{M}$. fructicola isolates from New York during 2005 to 2007 to Pristine. Amiri et al. (1) investigated QoI re- sistance in 157 M. fructicola isolates collected between 2006 and 2008 in the southern United States and noticed an increase of three-, two-, five-, and twofold of the $\mathrm{EC}_{50}$ values to azoxystrobin, pyraclostrobin, boscalid, and pyraclostrobin + boscalid, respectively. Schnabel et al. (31) reported baseline data for azoxystrobin up to $1.35 \mu \mathrm{g} / \mathrm{ml}$ with SHAM at $100 \mu \mathrm{g} / \mathrm{ml}$. It is possible that the high $\mathrm{EC}_{50}$ values found in this study are a result of the lower concentration of SHAM in the test media which, for some isolates, may allow significant growth in vitro due to alternative oxidase activity. Interestingly, resistance of these isolates to azoxystrobin vanished when selection pressure was absent. That indicated that the mechanism should not be based on permanent genetic modifications. The lack of point mutations in the $C y t b$ gene, the target gene of QoI fungicides, supports this hypothesis. One might speculate that transient induction of expression of membrane drug efflux proteins such as ATP-binding cassette and major facilitator superfamily transporter genes (17) may be involved. In Botrytis cinerea, a close relative of $M$. fructicola, preexisting resistance to QoIs was connected with the constitutive expression of the alternative oxidase in mitochondria (33). The regulatory system of respiration enables $B$. cinerea to switch promptly to the alternative pathway once the cytochrome pathway is blocked by QoI fungicides. Whatever the mechanism of transient resistance, the isolates experienced a fitness cost. Both transient resistance and fitness cost indicate that these isolates likely will be effectively controlled with common antiresistance management strategies.

DMI and SDHI fungicides have been important components of brown rot control strategies in stone fruit worldwide for more than 30 years. Monilinia spp. have been very slow to develop resistance to both chemical classes. Resistance to DMIs has only been reported recently in the United States, including South Carolina, Georgia, Ohio, New Jersey, and New York $(3,20)$, and in Brazil (26). Resistant isolates were not found in this study and the mean $\mathrm{EC}_{50}$ value for tebuconazole was $0.03 \mu \mathrm{g} / \mathrm{ml}$, which was comparable with mean $\mathrm{EC}_{50}$ values reported for other DMIs $(4,35,36)$. SDHI fungicides have been used in the United States as rotation partners with DMI fungicides. They are highly effective and reduced sensitivity has only been detected in a few locations in the Unites States (1). The mean $\mathrm{EC}_{50}$ value for boscalid was 1.02 $\mu \mathrm{g} / \mathrm{ml}$, ranging from 0.01 to $2.88 \mu \mathrm{g} / \mathrm{ml}$. This is higher than the mean $\mathrm{EC}_{50}$ value of $0.56 \mu \mathrm{g} / \mathrm{ml}$ reported in the Unites States (5). This discrepancy is likely a result of the different medium used in this study (MM).

In conclusion, field resistance to QoI, DMI, and SDHI fungicides is either nonexistent or not common in Chinese peach orchards and, thus, the use of these products should result in excellent brown rot control. Resistance to MBC fungicides is emerging and needs to be considered for the design of brown rot management strategies.

\section{Acknowledgments}

This work is supported by the Special Fund for Agro-Scientific Research in the Public Interest (number 201303023), and partially by the Project of National Natural Science Foundation of China (number 31371896).

\section{Literature Cited}

1. Amiri, A., Brannen, P., and Schnabel, G. 2010. Reduced sensitivity in Monilinia fructicola field isolates from South Carolina and Georgia to respiration inhibitor fungicides. Plant Dis. 94:737-743.

2. Anonymous. Supplemental Material at http://wenku.baidu.com/view/ 4d9d8814964bcf84b9d57bd9.html

3. Burnett, A., Lalancette, N., and McFarland, K. 2010. First report of the peach brown rot fungus Monilinia fructicola resistant to demethylation inhibitor fungicides in New Jersey. Plant Dis. 94:126-126.

4. Chen, F., Fan, J., Zhou, T., Liu, X., Liu, J., and Schnabel, G. 2012. Baseline sensitivity of Monilinia fructicola from China to the DMI fungicide SYPZ048 and analysis of DMI-resistant mutants. Plant Dis. 96:416-422.

5. Chen, F., Liu, X., Chen, S., Schnabel, E., and Schnabel, G. 2013. Characterization of Monilinia fructicola strains resistant to both propiconazole and boscalid. Plant Dis. 97:645-651.

6. Chen, F., Liu, X., and Schnabel, G. 2013. Field strains of Monilinia fructicola resistant to both MBC and DMI fungicides isolated from stone fruit orchards in the eastern United States. Plant Dis. 97:1063-1068. 
7. Elmer, P. A., and Gaunt, R. 1994. The biological characteristics of dicarboximide-resistant isolates of Monilinia fructicola from New Zealand stone-fruit orchards. Plant Pathol. 43:130-137.

8. Fan, H. L. 2009. The incidence and intergrated management of peach brown rot. Henannongye 12:28. (In Chinese.)

9. Fan, J., Fang, Y., and Guo, L. 2009. Sensitivity of Monilinia fructicola isolates to thiophanate-methyl and boscalid. Acta Phytophylac. Sin. 36:251256.

10. Fang, Y. L., Liu, P., and Guo, L.-Y. 2010. Sensitivity of Monilinia fructicola isolates to azoxystrobin [J]. J. Fruit Sci. 4:016.

11. Hong, C., Holtz, B. A., Morgan, D. P., and Michailides, T. J. 1997. Significance of thinned fruit as a source of the secondary inoculum of Monilinia fructicola in California nectarine orchards. Plant Dis. 81:519-524.

12. Hu, M. J., Cox, K. D., Schnabel, G., and Luo, C.-X. 2011. Monilinia species causing brown rot of peach in China. PLoS One 6:e24990.

13. JinYan, F., Yali, F., and LiYun, G. 2009. Sensitivity of Monilinia fructicola isolates to thiophanate-methyl and boscalid. Acta Phytophylac. Sin. 36:251256

14. Jones, A. L., and Ehret, G. R. 1976. Isolation and characterization of benomyl-tolerant strains of Monilinia fructicola. Plant Dis. Rep. 60:765769.

15. Katan, T., Elad, Y., and Yunis, H. 1989. Resistance to diethofencarb (NPC) in benomyl-resistant field isolates of Botrytis cinerea. Plant Pathol. 38:8692.

16. Koenraadt, H., Somerville, S. C., and Jones, A. 1992. Characterization of mutations in the beta-tubulin gene of benomyl-resistant field strains of Venturia inaequalis and other plant pathogenic fungi. Phytopathology 82:13481354.

17. Kretschmer, M., Leroch, M., Mosbach, A., Walker, A.-S., Fillinger, S., Mernke, D., Schoonbeek, H.-J., Pradier, J.-M., Leroux, P., and De Waard, M. A. 2009. Fungicide-driven evolution and molecular basis of multidrug resistance in field populations of the grey mould fungus Botrytis cinerea. PLoS Pathog. 5:e1000696.

18. Leroux, P., Chapeland, F., Desbrosses, D., and Gredt, M. 1999. Patterns of cross-resistance to fungicides in Botryotinia fuckeliana (Botrytis cinerea) isolates from French vineyards. Crop Prot. 18:687-697.

19. Lim, T. H., Chang, T. H., and Cha, B. 1999. Biological characteristics of benzimidazole-resistant and-sensitive isolates of Monilinia fructicola from peach fruits in Korea. Plant Pathol. J. 15:340-344.

20. Luo, C. X., Cox, K. D., Amiri, A., and Schnabel, G. 2008. Occurrence and detection of the DMI resistance-associated genetic element 'Mona' in Monilinia fructicola. Plant Dis. 92:1099-1103.

21. Luo, C. X., Hu, M. J., Jin, X., Yin, L. F., Bryson, P. K., and Schnabel, G. 2010. An intron in the cytochrome b gene of Monilinia fructicola mitigates the risk of resistance development to QoI fungicides. Pest Manage. Sci. 66:1308-1315
22. Luo, C. X., and Schnabel, G. 2008. Adaptation to fungicides in Monilinia fructicola isolates with different fungicide resistance phenotypes. Phytopathology 98:230-238.

23. Luo, Y., and Michailides, T. J. 2001. Risk analysis for latent infection of prune by Monilinia fructicola in California. Phytopathology 91:1197-1208.

24. Ma, Z., Yoshimura, M. A., Holtz, B. A., and Michailides, T. J. 2005. Characterization and PCR-based detection of benzimidazole-resistant isolates of Monilinia laxa in California. Pest Manage. Sci. 61:449-457.

25. Ma, Z., Yoshimura, M. A., and Michailides, T. J. 2003. Identification an characterization of benzimidazole resistance in Monilinia fructicola from stone fruit orchards in California. Appl. Environ. Microbiol. 69:7145-7152.

26. May De Mio, L. L., Luo, Y., and Michailides, T. J. 2011. Sensitivity of Monilinia fructicola from Brazil to tebuconazole, azoxystrobin, and thiophanate-methyl and implications for disease management. Plant Dis. 95:821-827.

27. Michailides, T., Ogawa, J., and Opgenorth, D. 1987. Shift of Monilinia spp. and distribution of isolates sensitive and resistant to benomyl in California prune and apricot orchards. Plant Dis. 71:893-896.

28. Penrose, L. 1990. Prolonged field persistence of resistance to benomyl in Monilinia fructicola. Crop Prot. 9:190-192.

29. Sanoamuang, N., and Gaunt, R. 1995. Persistence and fitness of carbendazim-and dicarboximide-resistant isolates of Monilinia fructicola (Wint.) Honey in flowers, shoots and fruit of stone fruit. Plant Pathol. 44:448-457.

30. Schnabel, G., Bryson, P. K., Bridges, W. C., and Brannen, P. M. 2004. Reduced sensitivity in Monilinia fructicola to propiconazole in Georgia and implications for disease management. Plant Dis. 88:1000-1004.

31. Schnabel, G., Dai, Q., and Paradkar, M. R. 2003. Cloning and expression analysis of the ATP-binding cassette transporter gene MFABC1 and the alternative oxidase gene MfAOX1 from Monilinia fructicola. Pest Manage. Sci. 59:1143-1151.

32. Szkolnik, M., and Gilpatrick, J. D. 1977. Tolerance of Monilinia fructicola to benomyl in western New York State orchards. Plant Dis. Rep. 61:654657.

33. Tamura, H., Mizutani, A., Yukioka, H., Miki, N., Ohba, K., and Masuko, M. 1999. Effect of the methoxyiminoacetamide fungicide, SSF129, on respiratory activity in Botrytis cinerea. Pestic. Sci. 55:681-686.

34. Villani, S., and Cox, K. 2008. QoI sensitivity and the prevalence of DMI resistance in NY populations of the brown rot pathogen Monilinia fructicola. (Abstr.) Phytopathology 98:S163.

35. Yoshimura, M., Luo, Y., Ma, Z., and Michailides, T. 2004. Resistance of Monilinia fructicola from stone fruit to thiophanate methyl, iprodione and tebuconazole. (Abstr.) Phytopathology 94:S155.

36. Zehr, E. I., Luszcz, L. A., Olien, W. C., Newall, W., and Toler, J. E. 1999. Reduced sensitivity in Monilinia fructicola to propiconazole following prolonged exposure in peach orchards. Plant Dis. 83:913-916. 